\title{
An approach for children's emergent literacy adaptive activities
}

\author{
Jaline Gonçalves Mombach ${ }^{1}$, Paulo Silas Severo de Souza ${ }^{2}$, \\ Fabrizzio A. M. N. Soares ${ }^{1}$, Fábio Diniz Rossi ${ }^{3}$, \\ Tiago Coelho Ferreto ${ }^{2}$, Lara Leal ${ }^{3}$ \\ ${ }^{1}$ Federal University of Goiás (UFG) - Goiânia - Brazil \\ ${ }^{2}$ Pontifical Catholic University of Rio Grande do Sul (PUCRS) - Porto Alegre - Brazil \\ ${ }^{3}$ Federal Institute of Education, Science and Technology Farroupilha - Alegrete - Brazil

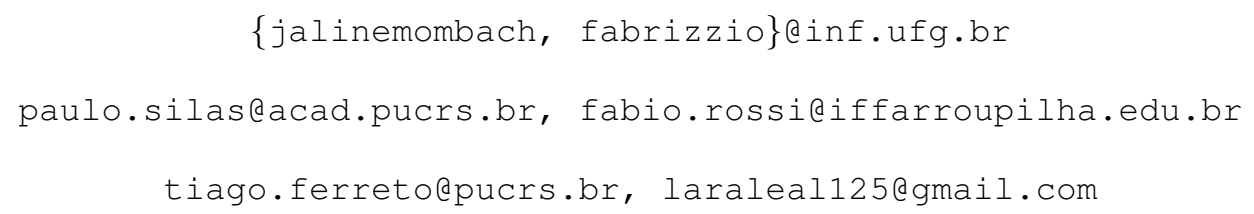

\begin{abstract}
In the educational field, there is a concern about helping children to develop emergent literacy skills such as reading and writing. However, this is not a trivial task since children may have different needs based on their skill levels. In this sense, we present an approach that employs mobile and cloud computing technology to adapt activities from different subjects according to children skill levels. Besides, our proposal generates assessment reports so teachers can monitor children achievement in real time. Experiments were conducted, and the results were positive, showing that our proposal could ease the development of adaptive activities and improve children engagement.
\end{abstract}

\section{Introduction}

Due to the popularization of the Internet and Information and Communication Technologies (ICTs), a growing amount of information is being produced every day. As a consequence, the ability to wisely selecting, interpreting, and manipulating information is being increasingly considered among the set of essential skills to achieve success [Genlott and Grönlund 2013].

Such a phenomenon is boosting researchers interest around the children's cognitive processes to improve learning outcomes and support the development of reading and writing skills. In this context, several investigations show that children construct their own understand about the writing system, and do not entirely mirror adult views of writing [Ferreiro and Teberosky 1986, Levin and Korat 1993, Sandbank 2001, Pontecorvo and Zucchermaglio 1988, Pontecorvo et al. 2014, Chan and Nunes 1998].

The process of developing reading and writing skills is known as emergent literacy and involves a set of skills and attitudes such as achieving a basic comprehension of the alphabet and getting phonological awareness. This knowledge is usually acquired at early childhood starting far early from school entry and have a direct impact on children future habits. For example, Interactions with books at early childhood may avoid children to struggle to read in the future [Whitehurst and Lonigan 1998, Stanovich 2009]. 
In the educational field, identifying the child's thinking, assessing their progress, and helping them broaden their vision about the writing system is a challenge. Vernon and Ferreiro describe that some tests classify children according to their ability to read texts correctly [Vernon and Ferreiro 1999]. However, emergent literacy has a broader spectrum, in which there are beginner writers, not just readers. When a child is asked to write something spontaneously, it is possible to observe a real process of construction.

Children begin school with widely varying levels of emergent literacy. Commonly Brazilian literacy teachers apply a test called "writing hypothesis test", which is based on Ferreiro and Teberosky theory [Ferreiro and Teberosky 1986]. A problem is a difficulty in finding technological resources to support performing this test. Nowadays, teachers themselves create their hypothesis tests, as well as the type of activity for each student, considering the level of writing in which they are.

Early childhood environment also has explored resources for learning. At the same time, Myrtil et al. report that tablets are widely adopted in this environment since they are lightweight and portable, allowing "anytime, anywhere" usage, as well as application's customization that enable teachers to meet the diverse range of needs within the classroom better [Myrtil et al. 2018].

Therefore, this work describes a technological approach based on Ferreiro and Teberosky theory to assist teachers in creating personalized literacy instructions at the writing level of each child [Ferreiro and Teberosky 1986]. Due to the specificity of this subject, our approach includes participatory design [Schuler and Namioka 1993] and a case study in a public school.

The remainder of this paper is organized as follows: Section II describes the psychogenesis of written language and children writing levels. In Section III, we introduce the proposed method, in Section IV we present experiment during the use of our proposal with literacy teachers, and in Section V we express the final remarks and topics to be addressed in future studies.

\section{Pedagogical foundations}

Ferreiro and Teberosky' studies began as experimental work and gave rise to theoretical assumptions about the psychogenesis of the writing system. This study became a milestone in the transformation of the concept of learning of writing in Brazil. Results of their research allow knowing how the child conceives the writing process, and the pedagogical and methodological theories point out ways to address the most frequent errors of literacy teachers [Ferreiro and Teberosky 1986].

During the assessment, the child is asked to write four different words and a sentence, all in Portuguese ${ }^{1}$ and one at a time. First, the polysyllable word, then a trisyllabic word, disyllabic word, monosyllabic word and end with a sentence. This order is because pre-literate children find it easier to write words that have more than two syllables. For the phrase, educators have to include one word already said previously to check if writing is consistent. Based on their responses, the educator can classify child levels of writing:

\footnotetext{
${ }^{1}$ Ferreiro and Teberosky [Ferreiro and Teberosky 1986] applied this thesis initially to Spanish-speaking children, but our proposal focuses in Brazil, to Portuguese-speaking children.
} 
VIII Congresso Brasileiro de Informática na Educação (CBIE 2019)

Anais do XXX Simpósio Brasileiro de Informática na Educação (SBIE 2019)

- Pre-syllabic: in the first phase, the beginning of this construction, the children's attempts are towards the reproductions of the earliest traces of the writing they encounter in everyday life. For example, it is common when asking the child to write the word dog, that she only draws a dog. Also, they can write several letters and then read the written string without analyzing it, no attempts to establish lettersound correspondences.

- Syllabic: in the second phase, each plotted stroke corresponds to a pronounced syllable. After this perception, the learner perceives a conflict between the syllabic hypothesis and the minimum number of letters required for the writing to be obtained, thus reaching the next phase. It is divided this level in both: without the use of appropriate letters and using appropriate letters (when there is phonetic correspondence). In the first case, they use any letter to represent any given syllable. For example, the child writes the word macaco (monkey) as IOA, reading " $m a$ ca-co" while pointing to one letter for each syllable. On the other hand, some children can write the same word as AAO, reading alike but with pertinent letters, using a vowel or a consonant that correctly composes each syllable.

- Syllabic-alphabetic: in the third phase, the transition from the syllabic to alphabetic hypothesis occurs, in which the child comes to realize that writing is to represent the sound parts of the words progressively, even if it does not do it in an entirely correct way. For example, a child writes the word macaco (monkey) as MACAO, with incomplete last syllable. It is possible she read pointing to one letter for each syllable or with a continuous gesture for the word because It is a level of transition.

- Alphabetic: in the final phase, the child already understands the system of representation of writing, even if with misspellings. For example, a child writes the word raposa (fox) as RAPOZA because in Portuguese the letters $\mathrm{S}$ and $\mathrm{Z}$ can correspond to the same sound.

Moreover, we highlight that identifying the child's level of writing is a strategy relevant to teachers so that they can adapt the different tasks to the needs of each student. For example, a pre-syllabic child will receive activities that encourage her to perceive the difference between drawings and numbers, and letters. On the other hand, the syllabic child may be invited to realize that syllables are not composed of only one word. Finally, alphabetical children should be encouraged to write the whole word and perceive proper orthographic differences of the language, already in an advanced stage of literacy.

\section{Related Work}

Reading and Writing skills play an essential role in children's development since issues regarding those skills may lead to severe consequences as elements that require enhanced literacy skills such as the Internet and Information and Communication Technologies (ICT) are becoming more and more popular [Genlott and Grönlund 2013]. In this sense, there has been a growing concern in the scientific field about finding ways to improve children literacy skills:

Shamir and Korat emphasize that the increasing inclusion of technology even in the kindergarten and children early contact to software brings opportunities such as the use of computer-assisted learning strategies. In this sense, the authors focus on evaluating 
VIII Congresso Brasileiro de Informática na Educação (CBIE 2019)

Anais do XXX Simpósio Brasileiro de Informática na Educação (SBIE 2019)

the effectiveness of an electronic book (e-book) to support the development of children language and literacy skills. Experiments were conducted with 72 kindergartner children, and the results showed improvements in children's overall emergent literacy levels [Shamir and Korat 2007].

Elliott and Olliff argue that the demand for children to have several requisite skills before kindergarten boosted the discussion around strategies to support the development of children pre-reading and writing skills. As a consequence, approaches such as the Early Literacy and Learning Model (ELLM) were developed to improve the language and pre-literacy skills of young children 3-5 years old. In this context, the authors present an analysis of the impact caused by the ELLM program to the development of basic letter recognition skills of 2 and 3 years old children [Elliott and Olliff 2008].

Genlott and Grönlund discuss the ever-increasing relevance of reading and writing skills due to the growing popularity of technology, which requires literacy skills to find, select, interpret, analyze, and produce relevant information. Thus, the authors present Integrated Write to Learn (iWTR), a method that focuses on bringing computers and other ICT tools to school to improve children literacy skills. The authors tested iWTR, and the results showed that it could enhance children reading and writing skills [Genlott and Grönlund 2013].

Massetti highlights that improving children's literacy skills has been considered as a top-priority goal by researchers and educational politics. Among the examples, the author the development of policies and projects such as the Stony Brook Emergent Literacy Project, that focus on combining teacher training practices, classroom-based activities, and scoring rubrics to evaluate children's performance on activities. Thus, the author assesses the impact caused by the Stony Brook Emergent Literacy Project on 10 head start classrooms. The results showed that the evaluated project could improve several children emergent literacy skills such as letter recognition [Massetti 2009].

To the best of our knowledge, no previous study focused on helping teachers to improve children emergent literacy skills through activities adapted according to children's level of writing. Thus, in this paper, we present an approach that helps teachers to provide adaptive exercises according to children skill levels. Besides, our proposal allows teachers to chose the activities subject and can be employed in different languages. Table 1 summarizes the main contributions of our proposal.

\section{Proposed Approach}

One of the most prominent subjects in the educational field is adaptive learning, since it is essential to mediate learning according to the specific needs of each student [Waxman et al. 1985, Vogt and Rogalla 2009], and in emergent literacy, this is no different. However, this generates a high workload for the teacher, who in real practice often has classes with 20 or 30 students and because this, it is difficult to elaborate activities of different levels, keeping the same subject worked in the classroom. It is more critical when we consider that each language has its specific characteristics, with varying levels of writing.

Based on such a scenario, the main question is: "how technological resources might support teacher to create adaptive tasks for early childhood literacy?". To answer 
VIII Congresso Brasileiro de Informática na Educação (CBIE 2019)

Anais do XXX Simpósio Brasileiro de Informática na Educação (SBIE 2019)

Table 1. Comparison among previous studies and our proposal.

\begin{tabular}{|l|l|l|l|l|l|}
\hline \multicolumn{2}{|c|}{ Features } & \multicolumn{5}{|c|}{ Studies } \\
\cline { 2 - 6 } & $\begin{array}{l}\text { Shamir } \\
\text { and } \\
\text { Korat } \\
(2017)\end{array}$ & $\begin{array}{l}\text { Elliott } \\
\text { and } \\
\text { Olliff } \\
(2008)\end{array}$ & $\begin{array}{l}\text { Genlott } \\
\text { and } \\
\text { Gronlund } \\
(2013)\end{array}$ & $\begin{array}{l}\text { Massetti } \\
(2009)\end{array}$ & $\begin{array}{l}\text { Our } \\
\text { Proposal }\end{array}$ \\
\hline $\begin{array}{l}\text { Provides support to } \\
\text { multiple languages }\end{array}$ & $\mathrm{x}$ & $\mathrm{x}$ & $\mathrm{x}$ & $\mathrm{x}$ & $\mathbf{x}$ \\
\hline $\begin{array}{l}\text { Allows teachers to } \\
\text { chose different types of } \\
\text { activities }\end{array}$ & $\mathrm{x}$ & $\mathrm{x}$ & $\mathrm{x}$ \\
\hline $\begin{array}{l}\text { Generates reports about } \\
\text { children's progress }\end{array}$ & & $\mathrm{x}$ & $\mathrm{x}$ & $\mathrm{x}$ & $\mathbf{x}$ \\
\hline $\begin{array}{l}\text { Allows teachers to cre- } \\
\text { ate customized activity } \\
\text { subjects }\end{array}$ & & & & & $\mathbf{x}$ \\
\hline
\end{tabular}

this question, we begin by taking a close look at theories are about the psychogenesis of the written language [Ferreiro and Teberosky 1986]. It is noticeable that teachers adopt a method and classify the writing levels of his students according to the thesis that he believes. So let's emphasize that teacher intervention for the development of personalized activities is paramount.

Therefore, we have developed an approach that seeks to bring the teacher closer to technology and to keep his as the holder of knowledge. Thus, the teacher needs to create activity templates and suggest to technology how it can adapt it to the different levels of writing that he uses. So, our proposal has five steps for creating the tasks, as shown in Figure 1.

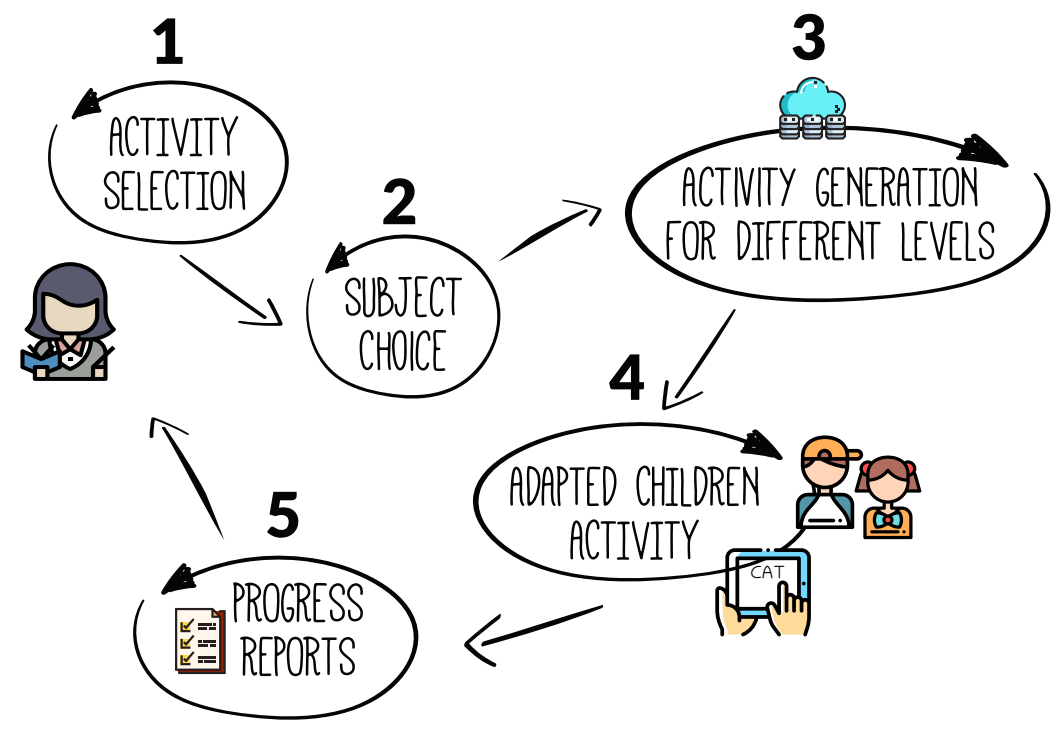

Figure 1. Steps for generating literate activities adapted to the child's level 
1. Activity selection: at this stage, teachers can select a template of literacy activity in a database. Each template in the database is shared among all teachers that use our proposal in order to facilitate the knowledge exchange.

2. Subject Choice: after selecting an activity template, it is essential that the teacher chooses what the subject of the activity. Some studies show that the subject needs to be meaningful for the child and also follow the same semantic field, such as fruits, animals, school material, among others.

3. Activity generation for different levels: at this stage, the teacher should answer some questions that will be used by the proposed platform to determine the child skill level.

4. Adapted children activity: after the teacher generates the adapted activities, you can link the level to each student and thus, when the child starts the task, on your tablet the task will already be customized according to your learning needs.

5. Progress Report: finally when the children finish the task, the teacher can generate a report with the correct answers and mistakes of each student to follow their progress.

Besides, in activity generation for different levels, teachers can add new rules according to writing skill level conventions from different languages. For example, teachers following the written language psychogenesis could answer the following features:

- the child does not differ from letters of numbers and drawings;

- the child indiscriminately uses letters, with no phonetic association;

- the child does not identify the initial letter of the words;

- the child identifies only the initial letter of the words;

- the child does not identify the number of syllables of the words;

- the child writes some syllables incompletely;

- the child writes the words, but with some grammatical errors.

In this way, the teacher requests that the tool generate the same activity, but at different levels, according to the rules that he established. Following the rules, a task can only show pictures and ask the child to write the word, another can generate gaps in the initial and final letter for the child to complete, another can show letters and ask the child to select the one corresponding to the initial letter of the drawing, among other possible differences pointed out by the teachers.

In summary, we consider as the differential of our approach: (i) participatory development, including literacy teachers; (ii) the pedagogical proposal is well defined and with the integration of activities ranging from the recognition of traits to writing; (iii) the possibility of use in different touch-sensitive devices; (iv) monitoring of student progress by teacher. Therefore, a case study in the Brazilian context is described next.

\section{Case Study}

To test our approach, we look out for schools interested in this issue. Thus, we chose a small primary education school, located in the rural area of the countryside of Brazil. To understand the problem and generate the activities, we held a workshop with the teachers of this school, such as bellow. 
VIII Congresso Brasileiro de Informática na Educação (CBIE 2019)

Anais do XXX Simpósio Brasileiro de Informática na Educação (SBIE 2019)

\subsection{Workshop for teachers}

Initially, we held a workshop with teachers and the school's pedagogical team, a group of 10 educators. The teachers explained how the writing tests and the existing demand were performed to adapt the activities according to the needs of each child. Currently, teachers do these tasks manually, and one problem is the time they spend doing the customization of activities.

Also, teachers urged that the approach is implemented for use in tablets because the government distributed some educational tablets in schools, but these were idle. So, teachers did not effectively use the technology in the classroom. On the other hand, teachers were unsure of replicating the paper experience on the tablet. Notably, they expressed interest in testing the activities already carried out on paper in a digital version with the students, before project continuing.

To ensure that the application meets the needs of teachers, we use some participatory design techniques. Participatory Design is a collaborative approach provides for active participation and user interaction during a project development [Dust and Jonsdatter 2008]. In this way, we divide the project into incremental steps, including meetings with teachers.

\subsubsection{Activities collection to database}

As a first step in the proposal, we need literacy activity templates for each level. For this, we asked the teachers to elaborate in paper different activities that usually applied with their students, indicating to which writing level the task would be more appropriate. In Figure 2 we can see examples of these exercises created by teachers during the workshop.

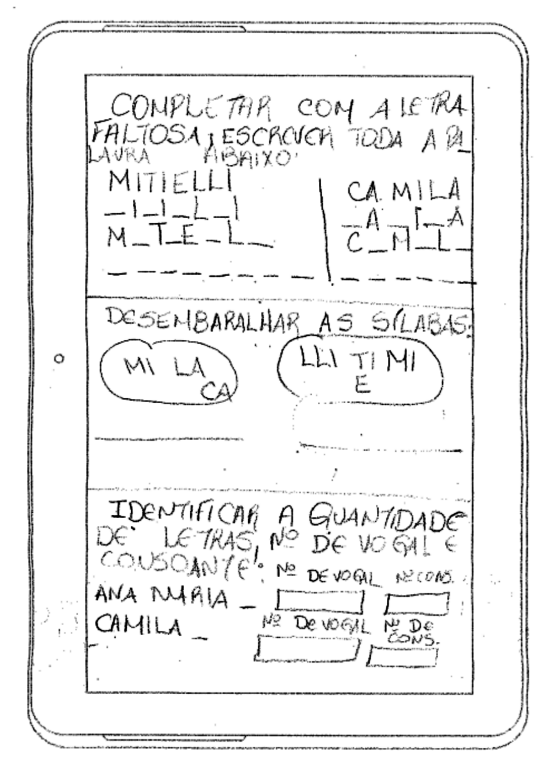

(a)

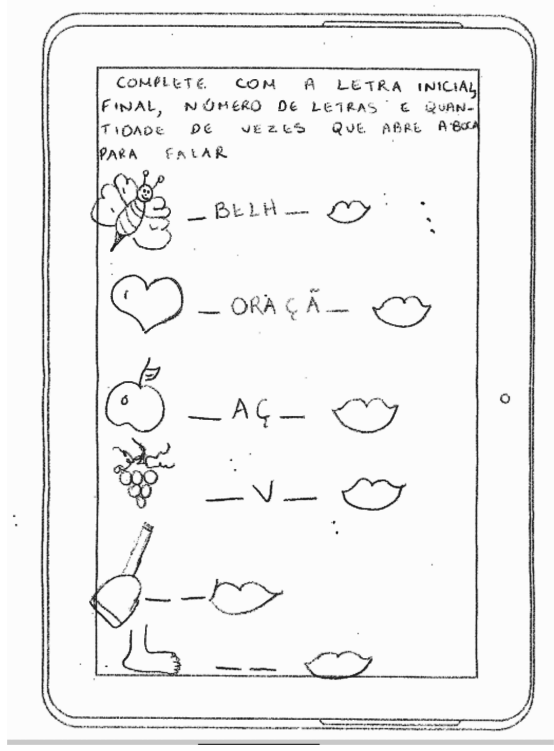

(b)

Figure 2. Prototypes' examples created by literacy teachers for different writing levels: (a) Pre-syllabic; (b) Syllabic. 
VIII Congresso Brasileiro de Informática na Educação (CBIE 2019)

Anais do XXX Simpósio Brasileiro de Informática na Educação (SBIE 2019)

After getting a collection of literacy activities, we began the process of creating digital versions of these tasks for use on tablets.

\subsection{Design and evaluate of prototype}

To evaluate whether it was feasible to convert paper activities into digital versions, we implemented a prototype using MIT App Inventor ${ }^{2}$ in a workshop with teachers. This tool was chosen because we analyzed the technologies available for the creation of mobile applications and, due to the Participatory Design, listed as a criterion the ease of understanding by the participating teachers of the project. Figure 3 shows activities' screenshots created in the prototype, following the models provided by teachers.

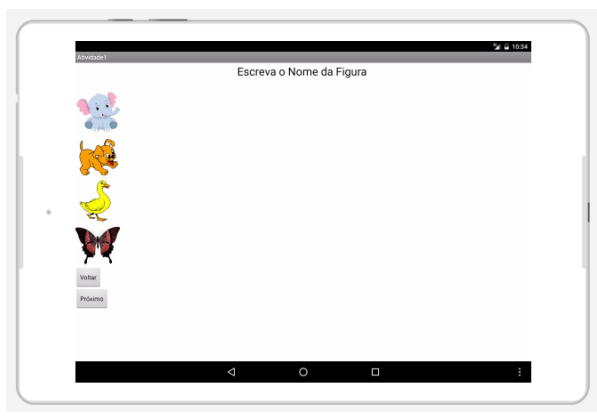

(a)

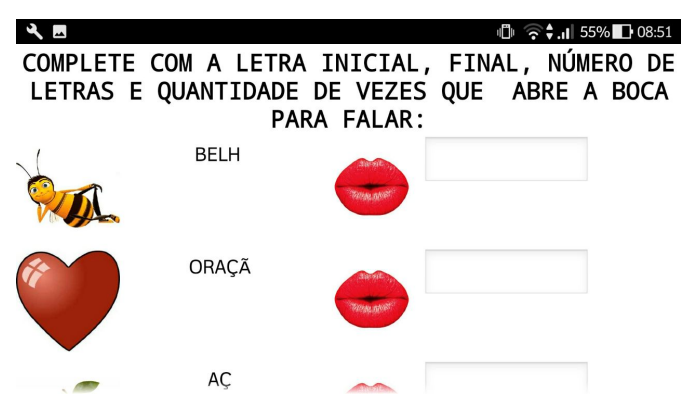

(b)

Figure 3. Activities' transposition created in paper for digital version on tablet: (a) Presyllabic level; (b) Syllabic level.

\subsubsection{Prototype test}

As explained previously, teachers were uncertain about the effectiveness of the approach because it is a proposal to implement literacy activities using tablets.

Therefore, a crucial step was to enable them to test the prototype with their students. For this to occur, two teachers participated in this stage and applied the task to their students. As shown in Figure 4, teachers tested the application together with the children.
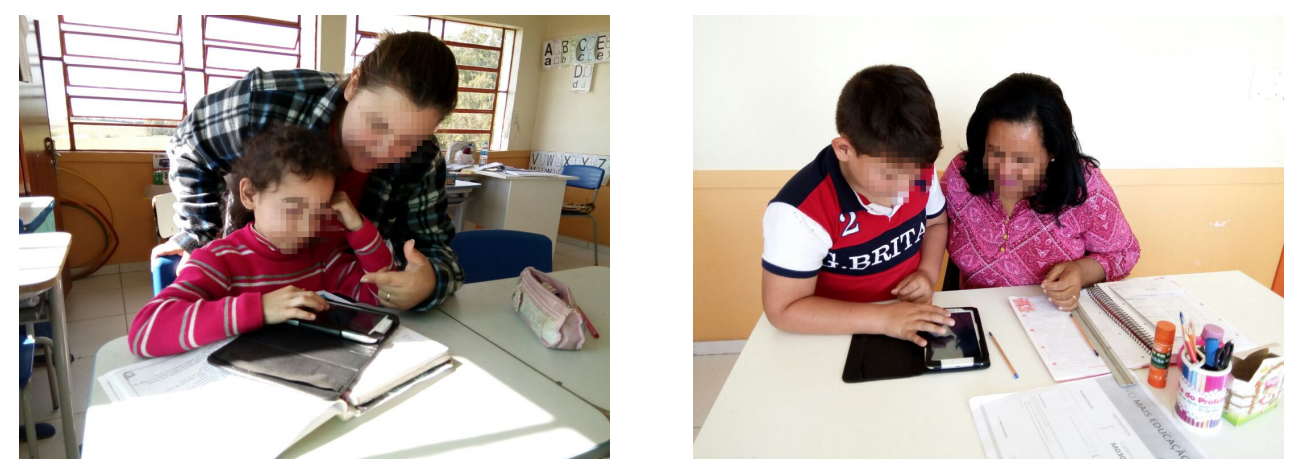

Figure 4. Teachers testing the prototype with their students.

\footnotetext{
${ }^{2}$ MIT App Inventor. Available at: $<$ http://appinventor.mit.edu $>$.
} 
The children showed interest and animation to perform the activity mainly due to the use of a tablet, an unconventional learning resource in the classroom. We also realized that the addition of sounds and colorful figures made the task more attractive to them. After testing the prototype, teachers responded to a short questionnaire drawn up using a Likert's scale (strongly agree, agree, neutral, disagree, strongly disagree) to measure their level of agreement with the statements:

- Teacher can adapt the tasks according to the student's writing hypothesis.

- The proposal covers the main stages of writing psychogenesis.

- Students were able to carry out the activities as expected.

- Students were able to adapt well to the exchange of paper by the tablet to perform the task.

- I believe the application can contribute to the teaching profession.

Teachers replied that they agreed with all the statements. Besides, when asked about what they liked most about the application and possible limitations of the proposal, we received the reports: "With the app, I realized that there was a more significant interest in the child in carrying out the proposed activities", and "The main limitation of approach is access to instrument to use the app, because not everyone has access to the tablets".

\section{Conclusions}

Writing and reading skills are fundamental to children's success not only in school but in their life trajectory. Besides, studies show that the foundation of reading and writing skills are set before the child enters kindergarten [Schirmer 2008]. In this sense, there is a concern on developing strategies to support the development of children pre-reading and writing skills. However, supporting the development of emergent literacy skills is not trivial since children may have different needs based on their skill levels.

In this sense, we present an approach that combines mobile and cloud computing technology to support teachers in the development of activities that are adapted according to children skill levels. Firstly, teachers select the type and the subject of the activity, then students can access the activity through mobile devices such as tablets or smartphones. As soon children finish their activities, teachers receive a report about children's achievement.

Our approach uses a language-agnostic strategy that allows teachers to create activities in languages that employ different writing skill levels. We conducted experiments to evaluate our proposal, and the results showed that it could improve children engagement through the playfulness brought by mobile devices. Besides, teachers expressed their approval to the proposed approach, highlighting the increases in children achievement. As future work, we intend to employ machine learning mechanisms to enhance the detection of children writing skill level.

\section{References}

Chan, L. and Nunes, T. (1998). Children's understanding of the formal and functional characteristics of written chinese. Applied Psycholinguistics, 19(1):115-131.

Dust, F. and Jonsdatter, G. (2008). Design Dictionary: Perspectives on Design Terminology, chapter Participatory Design, pages 290-292. Birkhäuser Basel, Basel. 
VIII Congresso Brasileiro de Informática na Educação (CBIE 2019)

Anais do XXX Simpósio Brasileiro de Informática na Educação (SBIE 2019)

Elliott, E. M. and Olliff, C. B. (2008). Developmentally appropriate emergent literacy activities for young children: Adapting the early literacy and learning model. Early Childhood Education Journal, 35(6):551-556.

Ferreiro, E. and Teberosky, A. (1986). Psicogênese da língua escrita. Artes Médicas.

Genlott, A. A. and Grönlund, Å. (2013). Improving literacy skills through learning reading by writing: The iwtr method presented and tested. Computers \& Education, 67:98104.

Levin, I. and Korat, O. (1993). Sensitivity to phonological, morphological, and semantic cues in early reading and writing in hebrew. Merrill-Palmer Quarterly (1982-), pages 213-232.

Massetti, G. M. (2009). Enhancing emergent literacy skills of preschoolers from lowincome environments through a classroom-based approach. School Psychology Review, 38(4).

Myrtil, M. J., Justice, L. M., Pelfrey, L., Logan, J. A., Xie, K., and Barnes, L. (2018). Preschool teachers' implementation fidelity when using a technology-mediated language and literacy intervention. Child \& Youth Care Forum, 47(6):771-786.

Pontecorvo, C., Orsolini, M., Burge, B., and Resnick, L. B. (2014). Children's early text construction. Routledge.

Pontecorvo, C. and Zucchermaglio, C. (1988). Modes of differentiation in children's writing construction. European Journal of Psychology of Education, 3(4):371.

Sandbank, A. (2001). On the interplay of genre and writing conventions in early text writing. In Developmental aspects in learning to write, pages 55-75. Springer.

Schirmer, B. R. (2008). How effectively are we preparing teacher educators in special education? the case of deaf education. American Annals of the Deaf, 153(4):411-419.

Schuler, D. and Namioka, A. (1993). Participatory design: Principles and practices. CRC Press.

Shamir, A. and Korat, O. (2007). Developing an educational e-book for fostering kindergarten children's emergent literacy. Computers in the Schools, 24(1-2):125-143.

Stanovich, K. E. (2009). Matthew effects in reading: Some consequences of individual differences in the acquisition of literacy. Journal of education, 189(1-2):23-55.

Vernon, S. and Ferreiro, E. (1999). Writing development: A neglected variable in the consideration of phonological awareness. Harvard Educational Review, 69(4):395416.

Vogt, F. and Rogalla, M. (2009). Developing adaptive teaching competency through coaching. Teaching and Teacher Education, 25(8):1051-1060.

Waxman, H. C. et al. (1985). Synthesis of research on the effects of adaptive education. Educational leadership, 43(1):26-29.

Whitehurst, G. J. and Lonigan, C. J. (1998). Child development and emergent literacy. Child development, 69(3):848-872. 